\title{
Serum Leptin Level and Thyroid Hormone in Type 2 Diabetes Patients
}

\author{
Hamza Mustaffa Khuder ${ }^{1}$, Khudair Abbas Khudair ${ }^{2}$, Ammar Lateef Hussein ${ }^{3}$ \\ ${ }^{1}$ Student, Bachelor of Medical Lab Science, Collage of Technology, Kirkuk, ${ }^{2}$ Ass. Prof. Tikrit Medical College, \\ Community Medicine, ${ }^{3}$ Ass. Prof. Tikrit Medical College, Community Medicine
}

\begin{abstract}
Background: Diabetes is a complex, chronic illness requiring continuous medical care with multi-factorial risk-reduction strategies beyond glycemic control. Ongoing diabetes self-management education and support are critical to preventing acute complications and reducing the risk of long term complications ${ }^{(1)}$. Diabetes mellitus occurs when there are raised levels of glucose in aperson's blood because their body cannot produceany or enough of the hormone insulin, or cannot effectively use the insulin it produces. The causes of type 2 diabetes are not completely understood but there is a strong link with overweight and obesity, and increasing age, as well as with ethnicity and family history.Aim: This study intended to assess and study correlation between serum levels of leptin and thyroid hormones in diabetic and obese patients.Subject and Method:a case control study was conducted at the center of diabetes management and research between $1^{\text {st }}$ of December 2019 to the $15^{\text {th }}$ of May 2020. A fasting blood sample was taken from all participants for measurement of biochemical parameters. The information regarding the problem and demographic characteristics was obtained directly from the participants by interviewing them, using a prepared questionnaire. The weight and the height were using a medical scale machine. The body mass index was calculated according to its equation.Results: Results of the present study show that leptin hormone was significantly high in serum of type 2 diabetic patients group compared with overweight and obese group ( $\mathrm{P}$ $<0.000)$. A significant positive correlation with serum leptin and body mass index. Results also show that TSH hormone $(\mathrm{P}<0.01)$, and FBS were significantly high $(\mathrm{P}<0.000)$, while $\mathrm{T} 3$ and $\mathrm{T} 4$ decrease significant $(\mathrm{P}<0.05)$ in type 2 diabetic patients groupand compared with control groups.
\end{abstract}

Keywords: Type 2 diabetes mellitus, Leptin, thyroid hormone.

\section{Introduction}

With the increasing incidence of obesity and type 2 diabetes mellitus in the Iraq and abroad, We should focused on the molecules and pathways that regulate metabolic homeostasis with the hope of identifying a pharmacological target to limit obesity and diabetes, and/or its pathophysiological consequences. Diabetes is a major health issue that has reached alarming levels: today, nearly half a billion people are living with diabetes worldwide $^{(1)}$. It is one of the major health priority of the 21 st century ${ }^{(2)}$ causing 1.5 million deaths in $2012^{(3)}$ and 4.2 million deaths resulting from diabetes and its complications in $2019^{(2)}$.Diabetes can be classified into the following general categories: Type 1 diabetes (due to autoimmune b-cell destruction, usually leading to absolute insulin deficiency), Type 2 diabetes (due to a progressive loss of adequate b-cell insulin secretion frequently on the background of insulin resistance) and Gestational diabetes mellitus ${ }^{(4)}$. Type 2 diabetes is most commonly seen in older adults, but is increasingly seen in children and younger adults owing to rising levels of obesity, physical inactivity and inappropriate $\operatorname{diet}^{(5,6)}$. In another word, a consequence of social trends toward higher energy intake and reduced energy expenditure ${ }^{(4,7)}$. Obesity is a rapidly growing health problem, conferring substantial excess risk for morbidity and mortality, especially from type 2 diabetes and atherosclerotic cardiovascular disease $(\mathrm{CVD})^{(8)}$. Studies on both humans and animal models have demonstrated close associations between obesity and a state of low-grade, chronic inflammation characterized by macrophage infiltration in adipose tissue and increased circulating 
concentrations of pro-inflammatory molecules, including acute-phase proteins, cytokines, adipokines (like leptin), and chemokines ${ }^{(9)}$. Leptin is a cytokinelike $(16 \mathrm{kDa})$ polypeptide produced by the adipocyte that controls food intake, leading to the suppression of appetite ${ }^{(10)}$, energy expenditure, and, hence, body weight through the activation of hypothalamic receptors $^{(11)}$. Women have higher leptin concentrations than men. But after menopause a significant reduction in the amount of circulating leptin occurs ${ }^{(12)}$. Such sexual differences can be explained by the difference in fat mass, body fat distribution, and sex hormones ${ }^{(13)}$. Mean concentration in women is $12.7 \mathrm{mg} / \mathrm{L}$ while it is $4.6 \mathrm{mg} / \mathrm{L}$ in $\mathrm{men}^{(14)}$.Leptin has been found increased in subjects with hyperinsulinemia and type 2 diabetes, and showed a positive association with triglycerides, systolic and diastolic blood pressure ${ }^{(15)}$. Within the endocrine system, leptin regulates the circadian rhythms of the gonadotropic, thyrotrophic and adrenal axes. It also plays key roles in the regulation of glucose homeostasis and insulin sensitivity, independent of actions on food intake, energy expenditure or body weight ${ }^{(16,17)}$. Also the hypothalamic _thyroidal axis is regulated by leptin. This provides an important interface between adiposity, regulated by leptin and metabolic rate, regulated by thyroid hormone ${ }^{(18)}$. Thyroid hormones play a very important role in controlling the body's metabolism, the rate at which the body uses energy, bystimulating divers metabolic activates most tissue, leading to an increase in basal metabolic rateone consequence of this activity is to increase body heat production ${ }^{(19)}$. So thyroid hormones with leptin might be involved in the adaptive thermo genesis $^{(20)}$.
Subjects and Method:A case control study was conducted at the center of diabetes management and research between $1^{\text {st }}$ of December 2019 to the $15^{\text {th }}$ of May 2020. The study include 100 subjects, divided into three groups: group 1: included 20 (11 male and 9 female) apparently healthy individuals whose body mass index (BMI) below $25 \mathrm{~kg} / \mathrm{m}^{2}$, age range 30-60 years, group 2: included 20 (8 male and 12 female) healthy individuals whose BMI equal or above to $25 \mathrm{~kg} /$ $\mathrm{m}^{2}$, age range 32-60 years, and group 3: included 60 (28 male and 32 female) newly diagnosed diabetic patients whose BMI equal or above to $25 \mathrm{~kg} / \mathrm{m}^{2}$, age range $35-66$ years.From all participants, a fasting blood sample was taken for measurement of fasting plasma glucose (FPG), glycated hemoglobin (HbAlc), lipid profile, serum leptin, thyroid hormones, thyroid stimulating hormone (TSH) and fasting insulin. Insulin resistance (IR), BMI and atherogenic index (AI) were calculated according to special equations.

Statistical Analysis:The data obtained in the current study was analyzed using statistical package for social science (SPSS) program version 26. Different descriptive statistical method were used to summarize and tabulate the data. ANOVA test were used to compare the mean difference of all parameters between the three groups. Duncan test were used to determine the non-homogenous group if the result of ANOVA test was significant. Furthermore independent 2 samples student t-test were used to compare the difference between each 2 groups.

\section{Results:}

Demographic and clinical characteristics of all participants in this study shown in table 1:

Table (1): Demographic and clinical characteristics of the participants.

\begin{tabular}{|l|c|c|c|}
\hline Characteristics & Group 1 (no. $=\mathbf{2 0})$ & Group 2 (no. $=\mathbf{2 0})$ & Group 3 (no. $=60)$ \\
\hline Age Range (Mean \pm SD) & $30-60(44.0 \pm 8.3)$ & $32-60(45.0 \pm 7.0)$ & $35-66(47.5 \pm 7.4)$ \\
\hline Male no. (\%) & $11(55)$ & $8(40)$ & $28(46.6)$ \\
\hline Female no. (\%) & $9(45)$ & $12(60)$ & $32(53.3)$ \\
\hline M : F ratio & $1.22: 1$ & $1: 1.5$ & $1: 1.14$ \\
\hline Family history: Presentsno.(\%) & $11(55)$ & $13(65)$ & $33(55)$ \\
\hline Family history: Absentno.(\%) & $9(45)$ & $7(35)$ & $27(45)$ \\
\hline BMI & $20.1-24.8(22.4 \pm 1.7)$ & $25.8-48.0$ & $26-50$ \\
Range (mean \pm SD) & & $(34.2 \pm 5.3)$ & $(32.9 \pm 6.3)$ \\
\hline
\end{tabular}


Different biochemical parameters in the studied groups are presented as mean \pm SD in table (2):

Table (2): Biochemical parameters in the studied groups

\begin{tabular}{|c|c|c|c|c|}
\hline \multirow{2}{*}{ Biochemical parameters } & Group 1 & Group 2 & Group 3 & \multirow{2}{*}{ p-value } \\
\hline & \multicolumn{3}{|c|}{ Mean \pm SD } & \\
\hline FBG & $96.4 \pm 12.0$ & $97.2 \pm 14.5$ & $209 \pm 53.1^{b c}$ & $<0.0001$ \\
\hline $\mathrm{HbAlc}$ & $4.9 \pm 0.3$ & $5.3 \pm 0.4$ & $8.97 \pm 1.76^{b c}$ & $<0.0001$ \\
\hline Fasting S.Insulin & $6.5 \pm 2.3$ & $13.2 \pm 9.0$ & $14.2 \pm 9.2$ & 0.001 \\
\hline HOMA-IR & $1.51 \pm 0.51$ & $3.23 \pm 2.55^{\mathrm{a}}$ & $7.11 \pm 4.14^{b c}$ & $<0.0001$ \\
\hline Fasting S. Leptin & $2.9 \pm 1.2$ & $33.8 \pm 29.0^{\mathrm{a}}$ & $20.6 \pm 12.5^{b}$ & $<0.0001$ \\
\hline T-cholesterol & $164.0 \pm 25.7$ & $179.7 \pm 44.7$ & $187.1 \pm 42.6^{\mathrm{b}}$ & 0.05 \\
\hline HDL- cholesterol & $49.8 \pm 9.0$ & $41.2 \pm 10.9^{\mathrm{a}}$ & $35.7 \pm 8.9^{b c}$ & $<0.0001$ \\
\hline LDL- cholesterol & $93.6 \pm 24.5$ & $106.4 \pm 36.6$ & $117.1 \pm 37.0^{\mathrm{b}}$ & $<0.05$ \\
\hline Triglyceride & $103.4 \pm 52.5$ & $148.1 \pm 66.4^{\mathrm{a}}$ & $171.1 \pm 59.6^{b}$ & $<0.0001$ \\
\hline A.I. & $3.4 \pm 1.0$ & $4.2 \pm 1.2$ & $5.6 \pm 2.3^{b}$ & $<0.0001$ \\
\hline $\mathrm{TSH}$ & $2.31 \pm 0.99$ & $4.51 \pm 2.55$ & $7.1 \pm 5.0^{\mathrm{bc}}$ & 0.01 \\
\hline $\mathrm{fT} 4$ & $1.09 \pm 0.28$ & $1.2 \pm 0.35$ & $1.54 \pm 0.71^{\mathrm{b}}$ & 0.05 \\
\hline f T3 & $1.31 \pm 0.59$ & $1.67 \pm 0.73$ & $2.09 \pm 0.82^{b}$ & 0.04 \\
\hline
\end{tabular}

${ }^{\mathrm{a}}=$ significant difference between group 2 and group $1 ;^{\mathrm{b}}=$ significant difference between group 3 and group $1 ;{ }^{\mathrm{c}}=$ significant difference between group 3 and group 2

There is a significant positive correlation between serum leptin and BMI was found indicating that the increase in the BMI is associated with increase in serum leptin level in group 2. table (3), fig.(1).

Table (3): Correlation between s. leptin level, glycemic control, thyroid hormone and other metabolic parameters in group 2.

\begin{tabular}{|l|c|c|c|}
\hline \multirow{2}{*}{ Characteristics } & \multicolumn{3}{|c|}{ Serum Leptin } \\
\cline { 2 - 4 } & $\mathbf{r}$ & $\mathbf{r}^{\mathbf{2}}$ & $\mathbf{p}$ \\
\hline Age & 0.360 & 0.129 & 0.119 \\
\hline BMI & $0.848^{*}$ & 0.719 & 0.000 \\
\hline FPG & 0.189 & 0.036 & 0.081 \\
\hline HbA1c & -0.399 & 0.159 & 0.805 \\
\hline Fasting S. Insulin & -0.059 & 0.003 & 0.827 \\
\hline HOMA-IR & -0.052 & 0.003 & 0.609 \\
\hline TC & 0.122 & 0.015 & 0.873 \\
\hline HDL & -0.038 & 0.001 & 0.552 \\
\hline LDL & 0.141 & 0.020 & 0.552 \\
\hline TG & 0.141 & 0.020 & 0.498 \\
\hline AI & 0.161 & 0.026 & 0.094 \\
\hline TSH & 0.385 & 0.148 & 0.017 \\
\hline f T4 & $-0.528^{* *}$ & 0.279 & 0.01 \\
\hline f T3 & $-0.489^{* *}$ & 0.239 & \\
\hline
\end{tabular}




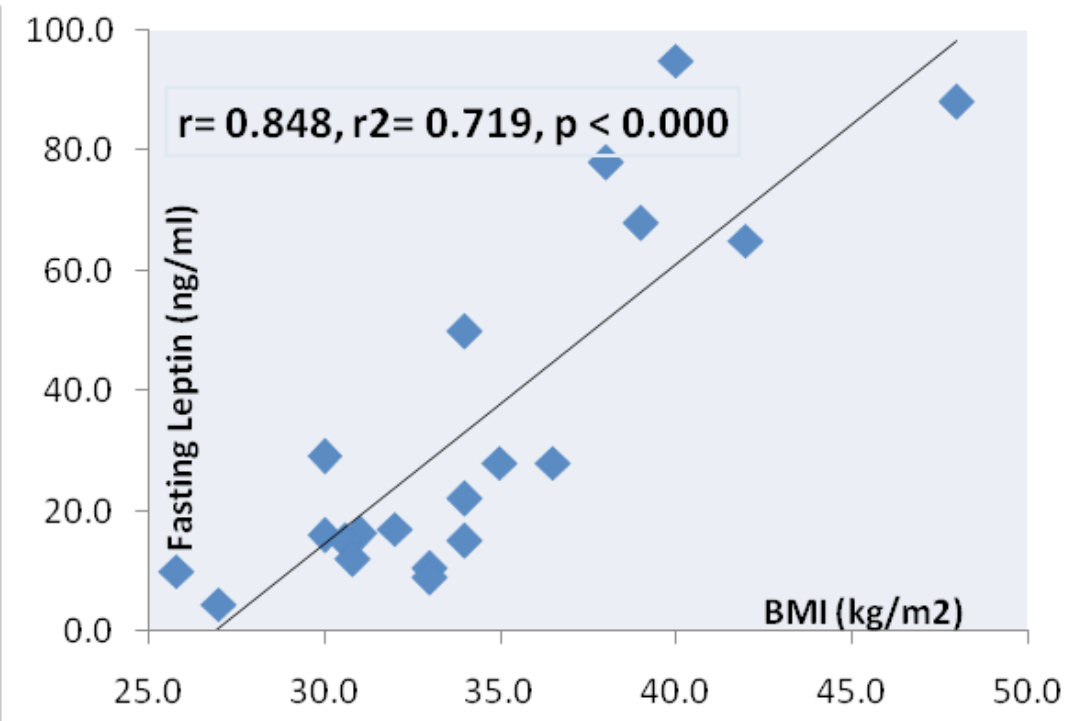

*Correlation is significant at the 0.01 level (2-tailed), ** Correlation is significant at the 0.05 level (2-tailed)

Figure(1): Correlation between serum leptin level BMI in group 2.

There is a significant positive correlation between serum leptin and BMI was found indicating that the increase in the BMI is associated with increase in serum leptin level and there was a significant negative correlation between serum leptin level and glycemic control (FBG and $\mathrm{HbAlc}$ ) which indicating that an increase in $\mathrm{FBG}$ and $\mathrm{HbAl} \mathrm{c}$ is associated with decrease in serum leptin level table (4), fig.(2).

Table (4): Correlation between serum leptin level, glycemic control, thyroid hormone and other metabolic parameters in group 3.

\begin{tabular}{|c|c|c|c|}
\hline \multirow{2}{*}{ Characteristics } & \multicolumn{3}{|c|}{ Serum Leptin } \\
\hline & $\mathbf{R}$ & $\mathbf{r}^{2}$ & $\mathbf{p}$ \\
\hline Age & 0.002 & 0.000 & 0.990 \\
\hline BMI & $0.687^{*}$ & 0.471 & 0.001 \\
\hline FPG & -0.241 & 0.058 & 0.044 \\
\hline $\mathrm{HbA1c}$ & -0.245 & 0.060 & 0.039 \\
\hline Fasting S. Insulin & $0.839^{*}$ & 0.705 & 0.000 \\
\hline HOMA-IR & $0.709^{*}$ & 0.503 & 0.000 \\
\hline $\mathrm{TC}$ & 0.053 & 0.003 & 0.687 \\
\hline HDL & -0.061 & 0.004 & 0.644 \\
\hline LDL & 0.088 & 0.008 & 0.504 \\
\hline TG & -0.038 & 0.001 & 0.774 \\
\hline AI & 0.071 & 0.005 & 0.592 \\
\hline $\mathrm{TSH}$ & 0.089 & 0.008 & 0.499 \\
\hline $\mathrm{fT} 4$ & -0.051 & 0.003 & 0.697 \\
\hline f T3 & -0.049 & 0.002 & 0.512 \\
\hline
\end{tabular}

*Correlation is significant at the 0.01 level (2-tailed) 


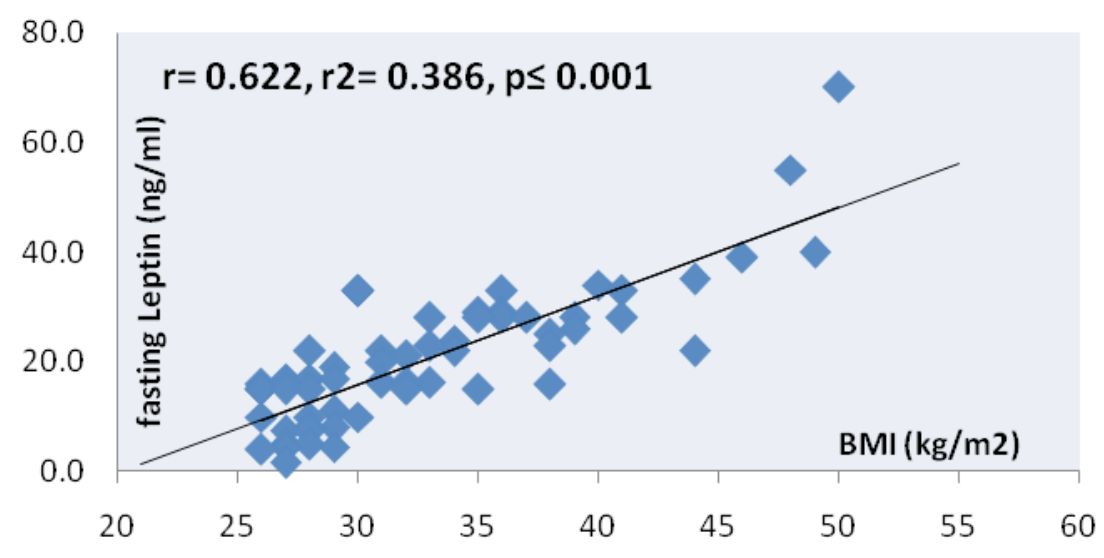

Figure (2): Correlation between serum leptin level BMI in group 3.

\section{Discussion}

The present study provides a wide view on biochemical features in blood of type 2 diabetic patients and non diabetic obese. Serum leptin determination and its correlation with other biochemical parameters were targeted in those groups. The mean age of type 2 diabetic patients who were participated in our study was (47.5 \pm 7.4 ) years coincides with the fact that type 2 diabetes mellitus usually develops after age 40 years $^{(21)}$.

In our study it was found that mean serum leptin level was higher in obese $(33.8 \pm 29.0)$ and diabetic groups $(20.6 \pm 12.5)$ than non-obese group $(2.9 \pm$ 1.2 ) and correlates positively and strongly with BMI $(p<0.001)$ in the three groups which is an important index of obesity. This finding was agreed with a study conducted in Baghdad, Iraq 2009, which compared a two groups, obese and non obese participants, and showed a positive correlation between leptin and BMI $(\mathrm{P}<0.01)$ (22). However, lower levels of leptin were observed in diabetes in study done to investigate the hormone resistance in diabetes and obesity ${ }^{(23)}$. This implies that the role of leptin in type 2 diabetes is controversial and still needs further investigation.

The mean $\mathrm{HbAlc}$ of $8.97 \%$ observed in T2DM patients and there was a significant difference in $\mathrm{HbA} 1 \mathrm{c}$ levels between the non diabetic groups and the diabetic group both had ( $p$ value $<0.000$ ). However we could not find, a significant difference in HbAlc levels between non diabetic groups, the obese and non obese patients, although it was obviously lower in the non obese patients implying a better glycemic status in such patients. This results similar to the result of case control study conducted in Iraq 2008 ${ }^{(24)}$.
A highly significant difference in insulin resistance (HOMA) was observed in diabetic group as compared to non obese group, which was expected because of the increased level of fasting plasma glucose and high level of serum insulin in diabetic patients, and there was a highly significant difference in insulin resistance (HOMA) was observed in obese group as compared to non obese group which was expected due to high level of serum insulin in obese group which indicate the presence of insulin resistance in this group. The result show a significant difference in insulin resistance ( $p$-value $<0.05)$ between diabetic and obese group.

The results of serum lipid profile in our study show that, cholesterol, triglycerides and LDL-C levels were significantly increased in diabetic patients and obese controls when compared to non obese controls whereas HDL-C level was significantly decreased in diabetics. Our study revealed no significant correlation between leptin and Total cholestrole, HDL-c, LDL-c, triglycerides and atherogenic index in all studied groups. These findings are in agreement with Assal et al. ${ }^{(25)}$ and Al-Shoumer et al. ${ }^{(26)}$, who showed no significant correlation between leptin and the lipid profile in diabetic patients, obese non diabetic and non obese non diabetic groups.

Obesity as a cause of insulin resistance may play a role in thyroid dysfunction. There is evidence that low free T4 is associated with insulin resistance ${ }^{(27)}$. Solanki et $\mathrm{al}^{(28)}$ reported significant correlation between BMI and TSH in healthy adults and BMI was negatively associated with serum fT4 but had no association with serum fT3. There is a positive association between TSH and obesity (BMI) which is similar to the result shown in Chinese study ${ }^{(29)}$ where they explain these result as 
an alterations in thyroid hormones activity or as a result of an alteration in the regulation of the hypothalamicpituitary-thyroid axis, and our results agreed with a study conducted in Saudi $2017^{(30)}$. In this study, the comparison of thyroid function between diabetic and the non obese group show a highly significant differences in TSH and fT4 ( $\mathrm{p}$ value $<0.01$ ) and a ( $\mathrm{p}$ value $<0.05$ ) for fT3. There is also a highly significant differences in TSH between obese and diabetic groups. These result agreed with a case control study conducted in the Diabetes and Endocrine Center at Al-Husain Teaching Hospital, ALMuthanna, Iraq 2015(31). Our results show a positive correlation between the level of leptin and TSH in both diabetic and obese group while showing a negative correlation in non obese group and it is reverse for both fT3 and fT4.

We conclude that there was increase in the BMI is associated with increase in serum leptin level.Patients with type 2 diabetes had significantly lower serum leptin compared with healthy subjects of the same BMI. Healthy subjects complaining from obesity are at a high risk of developing diabetes in the future concluded from the facts that their $\mathrm{HbA} 1 \mathrm{c}$ and IR was significantly higher compared with thin healthy control and highly significant difference in fasting serum insulin level. TSH show high level and a low levels of thyroid hormones in diabetic and obese participant compare with that of non obese group, i.e. TSH levels correlate with insulin resistance in obese patients.

Author's Contributions: Both authors played a key role in carrying out the study to conductive outcome. All authors were involved in the study design, data analysis, data collection,implementation of research and in the critical revision the final approval of manuscript.

Conflict of Interest: the authors declare that there are no conflict of interest.

\section{Source of Findings: Self}

Ethical Clearance: nil

\section{References}

1. Guariguata L, Whiting D, Weil C, Unwin N. The International Diabetes Federation Diabetes Atlas methodology for estimating global and national prevalence of diabetes in adults. Diabetes Res Clin Pract. 2011 Dec;94(3):322-32.

2. International Diabetes Federation. IDF Diabetes
Atlas, $9^{\text {th }}$ edition. Brussels; 2019.

3. World Health Organization (WHO). Global Report on Diabetes.World Health Organization, Geneva (Switzerland). 2016.

4. American Diabetes Association. 2. Classification and diagnosis of diabetes: Standards of Medical Care in Diabetes-2020. Diabetes Care. 2020;43(Suppl. 1):S14-S31

5. Gregg EW, Li Y, Wang J, Burrows NR, Ali MK, Rolka D, et al. Changes in diabetes-related complications in the United States, 1990-2010. N Engl J Med. 2014 Apr 17;370(16):1514- 23.

6. International Diabetes Federation. IDF Clinical practice recommendations for managing Type 2 diabetes in primary care. Brussels; 2019.

7. Zimmet P, Alberti KG, Shaw J. Global and societal implications of the diabetes epidemic. Nature. 2001;414:782-7.

8. Meigs JB, Wilson PW, Fox CS, Vasan RS, Nathan DM, Sullivan LM, et al. Body Mass Index, Metabolic Syndrome, and Risk of Type 2 Diabetes or Cardiovascular Disease. J Clin Endocrinol Metab. 2006; 91: 2906-2912.

9. Tataranni PA, Ortega E. A burning question: does an adipokine induced activation of the immune system mediate the effect of over nutrition on type 2 diabetes? Diabetes. 2005;54:917-27.

10. Mechanick JI, Zhao S, Garvey WT. Leptin, An Adipokine With Central Importance in the Global Obesity Problem. Glob Heart. 2017 Dec 13.

11. Brennan AM, Mantzoros CS. Drug Insight: The Role of Leptin in Human Physiology and Pathophysiology-Emerging Clinical Applications. Nat Clin Pract Endocrinol Metab. 2006; 2: 318-27.

12. Muller TD, Focker M, Holtkamp K, HerpertzDahlmann B, Hebebrand J. Leptin-mediated neuroendocrine alterations in anorexia nervosa: somatic and behavioral implications. Child and adolescent psychiatric clinics of North America. 2009;18(1):117-29.

13. Oleshchuk O, Loi H. Leptin resistance and type 2 diabetes. International Journal of Medicine and Medical Research. 2017; 3(1),15-21.

14. Efstratiadis, G.; Nikolaidou, C. and Vergoulas, G. Leptin as cardiovascular risk factor. Hippokratia. 2007;11: 163-170.

15. Uslu, S.; Kebapci, N.; Kara, M.; Bal, C. Relationship 
between adipocytokines and cardiovascular risk factors in patients with type 2 diabetes mellitus. Exp Ther Med. 2012; 4:113-120.

16. Brennan AM, Mantzoros CS. Drug Insight: The Role of Leptin in Human Physiology and Pathophysiology-Emerging Clinical Applications. Nat Clin Pract Endocrinol Metab. 2006; 2: 318-27.

17. Berglund ED, Vianna CR, Donato J Jr, Kim MH, Chuang JC, Lee CE, et al. Direct leptin action on POMC neurons regulates glucose homeostasis and hepatic insulin sensitivity in mice. J Clin Invest. 2012;122:1000-9.

18. Kim, M.S.; Small, G.J.; Stanley, S.A.; Morgan, D.G.; Seal, L.J.; Kong, W.M..et al. The central melanocortin system affects the hypothalamopituitary thyroid axis and may mediate the effect of Leptin. J Clin Invest. 2000;105: 1005-1011.

19. Choksi, N.Y.; Jahnka, G.D.; Hilaire, C.S. and Shelby, M. 2003. Role of Thyroid Hormones in human and Laboratory Animal Reproductive Health. Dev. Reprod. Toxicol. B.D.R. Stipanuk, M.H. 2000. Biochemical and Physiological Aspects of human nutrition. Saunders, Philadelphia.pp:763775.68: 479-491.

20. Zimmermann- Belsing T, Brabant G, Holst JJ, Rasmussen U. Circulating Leptin and thyroid dysfunction. Eur J Endocrinol.2003; 149:257-27.

21. Olokoba AB, Obateru OA, Olokoba LB. Type 2 diabetes mellitus: a review of current trends. Oman Med J. 2012; 27 (4): 269-273.

22. Turki KM, Alosami MH, Abdul-Qahar ZH. The effect of obesity on serum leptin and lipid profile. The iraqi postgraduate medical journal vol.1, no. 1, 2009
23. Flier JS. Hormone resistance in diabetes and obesity: insulin, leptin, and FGF21. Yale J Biol Med. 2012; 85 (3): 405-414.

24. Al -shamma ZA, Al-yassin HD, Hashim HM. Resistin, Insulin resistance and BMI in type 2 diabetes mellitus and healthy subjects. J Fac Med Baghdad Vol. 50, No. 3, 2008.

25. Assal HS, Fath-Alla M, Elsherbny A. Serum leptin and adiponectin in obese diabetic and non diabetic. J. Med.Sci.2007.7(5):865-869.

26. Al-Shoumer KA, Al-Asousi AA, Doi SA, Vasanthy BA. Serum leptin and its relationship with metabolic variables in Arabs with type 2 diabetes mellitus. Ann. Saudi Med.2008; 28:367-70.

27. Deetman PE, Bakker SJ, Kwakernaak AJ, Navis G, Dullaart RP. The relationship of the antioxidant bilirubin with free thyroxine is modified by insulin resistance in euthyroid subjects. PLoS One. 2014;9(3):e90886.

28. Solanki A, Bansal S, Jindal S, Saxena V, Shukla US. Relationship of serum thyroid stimulating hormone with body mass index in healthy adults. Indian J Endocrinol Metab. 2013;17(Suppl 1):S167-169.

29. Lin SY, Wang YY, Liu PH, Lai WA, Sheu WH. Lower serum free thyroxine levels are associated with metabolic syndrome in a Chinese population. Metabolism 2005; 54:1524-28.

30. Al-Musa HM. Impact of Obesity on Serum Levels of Thyroid Hormones among Euthyroid Saudi Adults. Hindawi Journal of thyroid Research Volume 2017, Article ID 5739806, 5 pages

31. Alzubaidy GH, Mousa TA. Relationship Between Leptin and Thyroid Hormones In Type 2 Diabetes Mellitus Patients. Journal of Babylon University,Pure and Applied Sciences. 2015; 2(23). 